\title{
Erratum zu: Astrid Baltruschat. Didaktische Unterrichtsforschung. Wiesbaden: Springer VS, 2018, 191 Seiten, $€$ 44,99 (ISBN: 978-3-658-17069-1)
}

\section{Rothland}

Online publiziert: 21. Juni 2021

(C) Der/die Autor(en) 2021

\section{Erratum zu:}

\section{Z f Bildungsforsch 2020}

https://doi.org/10.1007/s35834-020-00267-2

Die Rezension Astrid Baltruschat. Didaktische Unterrichtsforschung. Wiesbaden: Springer VS, 2018, 191 Seiten, $€$ 44,99 (ISBN: 978-3-658-17069-1) von Martin Rothland wurde ursprünglich Online First ohne „Open Access“ auf der Internetplattform des Verlags publiziert. Nach der Veröffentlichung in Bd. 10 Heft 1 pp. 125-130 hat sich der Autor für eine „Open Access“-Veröffentlichung entschieden. Das Urheberrecht des Artikels wurde deshalb in ( $)$ Der/die Autor(en) 2021 geändert.

Funding Funding Open Access funding enabled and organized by Projekt DEAL.

Open Access Dieser Artikel wird unter der Creative Commons Namensnennung 4.0 International Lizenz veröffentlicht, welche die Nutzung, Vervielfältigung, Bearbeitung, Verbreitung und Wiedergabe in jeglichem Medium und Format erlaubt, sofern Sie den/die ursprünglichen Autor(en) und die Quelle ordnungsgemäß nennen, einen Link zur Creative Commons Lizenz beifügen und angeben, ob Änderungen vorgenommen wurden.

Die Online-Version des Originalartikels ist unter https://doi.org/10.1007/s35834-020-00267-2 zu finden.

Prof. Dr. M. Rothland $(\bowtie)$

Fachbereich 06, Institut für Erziehungswissenschaft, Westfälische Wilhelms-Universität Münster, Bispinghof 5/6, 48143 Münster, Deutschland

E-Mail: Martin.Rothland@uni-muenster.de 
Die in diesem Artikel enthaltenen Bilder und sonstiges Drittmaterial unterliegen ebenfalls der genannten Creative Commons Lizenz, sofern sich aus der Abbildungslegende nichts anderes ergibt. Sofern das betreffende Material nicht unter der genannten Creative Commons Lizenz steht und die betreffende Handlung nicht nach gesetzlichen Vorschriften erlaubt ist, ist für die oben aufgeführten Weiterverwendungen des Materials die Einwilligung des jeweiligen Rechteinhabers einzuholen.

Weitere Details zur Lizenz entnehmen Sie bitte der Lizenzinformation auf http://creativecommons.org/ licenses/by/4.0/deed.de. 